\title{
Transparent fluorinate acrylic polyurethane with hydrophobicity obtained by crosslinking of hydroxyl-containing fluoroacrylate copolymer with HDI trimer
}

\author{
Yudi GuO, DONGYAN TANG*, FAN YANG \\ Department of Chemistry, Harbin Institute of Technology, Harbin 150001, China
}

\begin{abstract}
Hydroxyl-containing fluoroacrylate copolymers with different fluorine and hydroxyl concentrations were synthesized via free-radical solution polymerization. Transparent fluorinated polyurethane (FPU) films were prepared by curing the copolymers with HDI (hexamethylene diisocyanate) trimer. The Fourier transform infrared spectroscopy (FT-IR) results revealed introduction of fluorine both into the copolymer and polyurethane. X-ray photoelectron spectroscopy (XPS) analyses indicated that a gradient concentration of fluorine existed in the depth profile of the fluorinated polyurethane films. The highest contact angle (CA) was obtained for the FPU film with fluoroacrylate monomer concentration of $22 \mathrm{wt}$.\% because of fluorine present on the film surface. The surface topographies detected by SEM and AFM indicated that surface roughness contributed little to the film hydrophobicity. By increasing the fluoroacrylate monomer concentration, the decreasing of crosslinking degree of hard segment resulted in lowering the first degradation temperature, while more $\mathrm{C}-\mathrm{F}$ groups in soft segment led to higher second degradation temperature. UV-Vis spectrophotometer measurements indicated that the FPU film with the fluoroacrylate monomer concentration of $16 \mathrm{wt} . \%$ still had a high transmittance of more than $90 \%$ in the whole visible wavelength range.
\end{abstract}

Keywords: fluoroacrylate copolymer; polyurethane; hyrophobicity; transparency; X-ray photoelectron spectroscopy (XPS)

(C) Wroclaw University of Technology.

\section{Introduction}

Fluorinated polymers are attractive functional materials because of their excellent chemical and thermal stability [1], low surface energy [2], and low refractive index [3, 4]. Fluorinated acrylic polymers, especially with fluoroalkyl side chains are used as components for high performance paint and varnish in the textile, paper, leather, construction, automotive, aerospace industry, optics, and microelectronics [5-8]. The pendant $-\mathrm{CF}_{3}$ end groups on the fluoroalkyl side chains would segregate to the surface of polymer films, which would offer the polymer low surface free energy and good water-repellent properties. Moreover, the hydrophilic acrylic backbone would ensure the polymers good adhesion to various matrices [9-11]. Consequently, the synthesis of fluorinated acrylic

*E-mail: dytang@hit.edu.cn polymers, especially the synthesis of those with fluoroalkyl side chains, has attracted extensive interest for their unique properties and wide applications [12-14]. However, hydrophobicity and transparency are competitive properties from the viewpoint of surface roughness, which leads to extensive scattering of propagated light [15]. Thus, the sacrifice of transparency of the films by the introduction of fluorine into the structures restricts many applications of such hydrophobic materials for industrial usages, such as anti-wetting, antisnow (ice), adherence, anti-rusting, and reduced friction resistance $[16,17]$.

Up to now, many synthesis methods and techniques, such as initiated CVD [5], plasma deposition [18, 19], polymerization in $\mathrm{SC} \mathrm{CO}_{2}$ [20], have been developed and used for introducing the pendant $-\mathrm{CF}_{3}$ end groups into polymers for a waterrepellent surface. Special reaction conditions, expensive equipment and poor adhesion to substrates 
limit the application of these techniques in coating industry. It is important to achieve both the high hydrophobic and transparent surface by mature and simple synthesis route and technique.

In this work, a series of fluoroacrylate copolymers with $-\mathrm{OH}$ as the functional group reacting with $-\mathrm{NCO}$ to form fluorinated polyurethane were synthesized by free-radical solution polymerization. The hydroxyl-containing fluoroacrylate copolymer and fluorinated acrylic polyurethane were characterized by Fourier transform infrared spectra. The surface elements and topography were characterized using X-ray photoelectron spectroscopy (XPS), scanning electron microscopy (SEM) and atomic force microscopy (AFM). Thermogravimetry, contact angle detector and UV-Vis spectrophotometer were used to investigate the thermal stability, hydorphobicity and transparency of the FPU films.

\section{Experimental}

\subsection{Materials}

Desmodur® N 3390 BA (HDI trimer) obtained from Bayer Co., Ltd. was used as a curing agent for the preparation of fluorinated polyurethane. Methyl methacrylate (MMA, Tianjin Bodi Chemical Co., Ltd., CN), butyl acrylate (BA, Tianjin Chemical Reagent Institute, in analytical pure, CN), acrylic acid (AA, Tianjin Guangfu Fine Chemical Research Institute, $\mathrm{CN}$ ) and 2-hydroxypropyl acrylate (2-HPA, Changzhou Hickory Chemical Co., Ltd., CN) were the monomers used for the synthesis of copolymer. Dodecafluoroheptyl methacrylate (DFMA, $\mathrm{M}_{\mathrm{n}}: 400$ ) was supplied by Xeogia Fluorine-Silicon Chemical Co. Ltd. (CN) with the following structure:

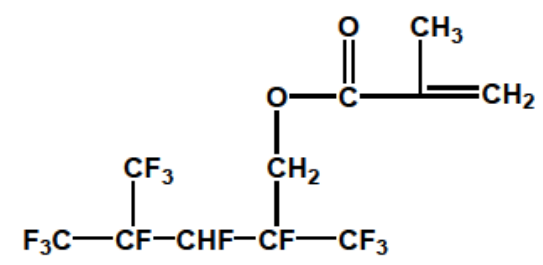

All the regents were used directly without further purification. Butyl acetate was used as a solvent and benzoyl peroxide (BPO) as an initiator in this work.

\subsection{Synthesis of hydroxyl-containing fluo- roacrylate copolymers}

The hydroxyl containing fluoroacrylate copolymer was synthesized by solution polymerization technique using BPO initiator (1 wt.\% based on total monomer weight) and $50 \mathrm{wt} \%$ solution of the monomer mixture in butyl acrylate for polymerization. All the polymerization steps were carried out in a four-neck bottomed flask with a mechanical stirrer, thermometer, reflux condensing tube and a dropping funnel. $80 \mathrm{wt} . \%$ of butyl acrylate was added to the flask and heated to the reaction temperature $\left(125 \pm 2{ }^{\circ} \mathrm{C}\right)$. Then, the monomers and $80 \mathrm{wt} . \%$ of initiator mixture was added dropwise under stirring within 2 hours and reacted for another 2 hours under stirring. Half of the rest $20 \mathrm{wt} . \%$ of the solvent and initiator mixture was added to the flask and reacted for 1.5 hours, and another half of the mixture was added then for another 1.5 hour. Table 1 shows the compositions for the synthesis of various fluoroacrylate copolymers.

Table 1. Compositions used for the synthesis of various fluoroacrylate copolymers.

\begin{tabular}{|c|c|c|c|c|c|c|}
\hline \multirow{2}{*}{ Samples } & \multicolumn{6}{|c|}{ Monomers (based on total monomer weight) } \\
\hline & MMA & BA & 2-HPA & DFMA & AA & $\mathrm{BPO}$ \\
\hline 1 & 44 & 34 & 20 & 0 & 1 & 1 \\
\hline 2 & 42 & 34 & 20 & 2 & 1 & 1 \\
\hline 3 & 36 & 34 & 20 & 8 & 1 & 1 \\
\hline 4 & 28 & 34 & 20 & 16 & 1 & 1 \\
\hline 5 & 22 & 34 & 20 & 22 & 1 & 1 \\
\hline 6 & 12 & 34 & 20 & 32 & 1 & 1 \\
\hline 7 & 0 & 34 & 20 & 44 & 1 & 1 \\
\hline
\end{tabular}

\subsection{Preparation of transparent fluori- nated acrylic polyurethane (FPU) films}

Transparent FPU films can be obtained by reaction of HDI trimer with hydroxyl-containing fluoroacrylate copolymers. Fig. 1 presents the preparation procedure of transparent FPU films. 


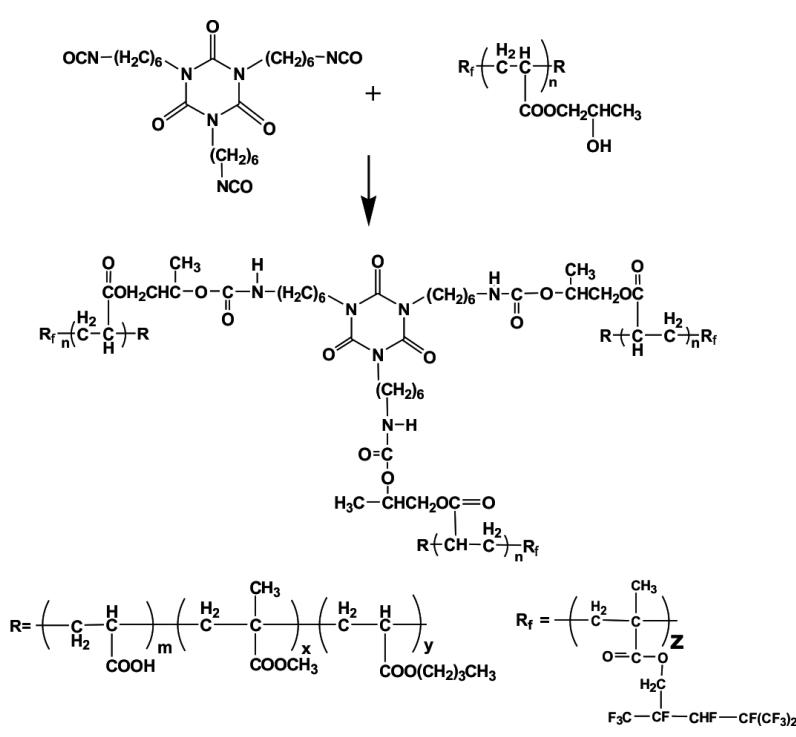

Fig. 1. The preparation procedure of transparent FPU films.

The hydroxyl-containing fluoroacrylate copolymer was mixed with Desmodur® N 3390 in the -NCO:-OH molar ratio of $1: 1$, and diluted with BA. After stirring thoroughly, the mixture was cast onto a glass slide for $30 \mathrm{~min}$ at room temperature and then cured at $80{ }^{\circ} \mathrm{C}$ for 4 hours. Series of FPU films with different fluoroacrylate monomer concentrations were prepared in this way.

\subsection{Measurements}

FT-IR spectra, obtained with an AVATER-360B FT-IR spectrometer (Nicolet Co., USA) in the range from $400 \mathrm{~cm}^{-1}$ to $4000 \mathrm{~cm}^{-1}$, were used to verify the existence of fluorine in the copolymers and FPU film. Surface elemental compositions of FPU films were determined by PHI 5700 ESCA systems (Physical Electronics, USA) employing an $\mathrm{AlK} \alpha \mathrm{X}$-ray source $(1486.6 \mathrm{eV})$ and a concentric hemispherical energy electron analyzer operating at $12.5 \mathrm{kV}$ and $250 \mathrm{~W}$ at the chamber pressure of $\sim 10^{-6}$ Torr. The survey spectra were recorded at the constant pass energy of $187.9 \mathrm{eV}$, and the high resolution analyses were conducted at the constant pass energy of $29.4 \mathrm{eV}$. The instrumental error in terms of the binding energy was within $\pm 0.1 \mathrm{eV}$. Data were recorded at different incident angles of $90^{\circ}$ and $30^{\circ}$ in order to probe both the surface and bulk features for the samples neutralized of charges. SEM (FEI, QUANTA200F, NL) and AFM (NT-MDT, Solver-P47, using a non contact tapping mode) images were used to study the morphology of FPU films. TG analyses were used to measure the thermostability of FPU films with Pyris 6 (Perkin-Elmer, USA) at a constant rate of $10{ }^{\circ} \mathrm{C} \cdot \mathrm{min}^{-1}$ at inert nitrogen atmosphere. Contact angles were measured by the sessile drop method at room temperature using a SL-200 contact angle goniometer (Solon (Shanghai) Information Technology Co., Ltd., CN). Typically, three drops of liquid were placed on the film surface and three readings of contact angles were taken for each drop. The average of nine readings was used as the final CA value for each sample. Wetting liquid used for contact angle measurements was super pure water and the injection volume was $2 \mu \mathrm{L}$. A TU-1901 UV-Vis spectrophotometer (Beijing Purkinje General Instrument Co., Ltd., CN) was used to measure the transmittance spectra of FPU films in the range of 190 to $900 \mathrm{~nm}$ wavelength light.

\section{Results and discussions}

\subsection{Characterization of structures of hydroxyl-containing fluoroacrylate copoly- mer and FPU films}

Fig. 2 shows the FT-IR spectra of hydroxylcontaining fluoroacrylate copolymer (a) and FPU film (b). The typical absorption peak of the fluoroacrylate copolymer at $3530 \mathrm{~cm}^{-1}$ indicates the existence of $-\mathrm{OH}$ functional group. The characteristic peak at $1734 \mathrm{~cm}^{-1}$ could be ascribed to the stretching vibration of $\mathrm{C}=\mathrm{O}$, and the peaks at 1450 and $1380 \mathrm{~cm}^{-1}$ are assigned to the distortion vibrations of $-\mathrm{CH}_{2}$. The absorption peaks at 530 to $710 \mathrm{~cm}^{-1}$ belong to the deformation vibrations of the $-\mathrm{CF}_{3}$, which indicates that the fluorine has been introduced into the copolymer. However, the stretching vibration of $\mathrm{C}-\mathrm{F}$ cannot be identified, which could be attributed to the overlap of peaks with that of C-O-C. As shown in Fig. 2b, the absorption peaks of amide I and amide II at 1690 and $1520 \mathrm{~cm}^{-1}$ and the adsorption peak of $-\mathrm{NH}$ at $3410 \mathrm{~cm}^{-1}$ indicate the complete reaction between $-\mathrm{NCO}$ groups and $-\mathrm{OH}$ groups. 


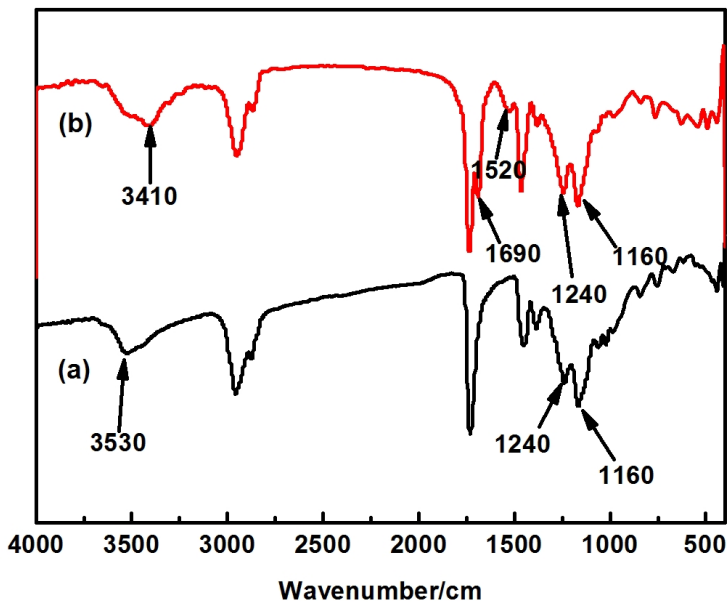

Fig. 2. FT-IR spectra of sample 6 (a) and the corresponding FPU film (b).

\subsection{Surface chemical compositions an- alysis}

The XPS measurements were carried out to determine the surface chemical compositions of FPU films. Fig. 3 shows the XPS survey spectra of FPU film obtained for sample 6 at $30^{\circ}$ and $90^{\circ}$ incident angles. As shown in Fig. 3, characteristic signal of fluorine at $30^{\circ}$ is stronger than that at $90^{\circ}$.

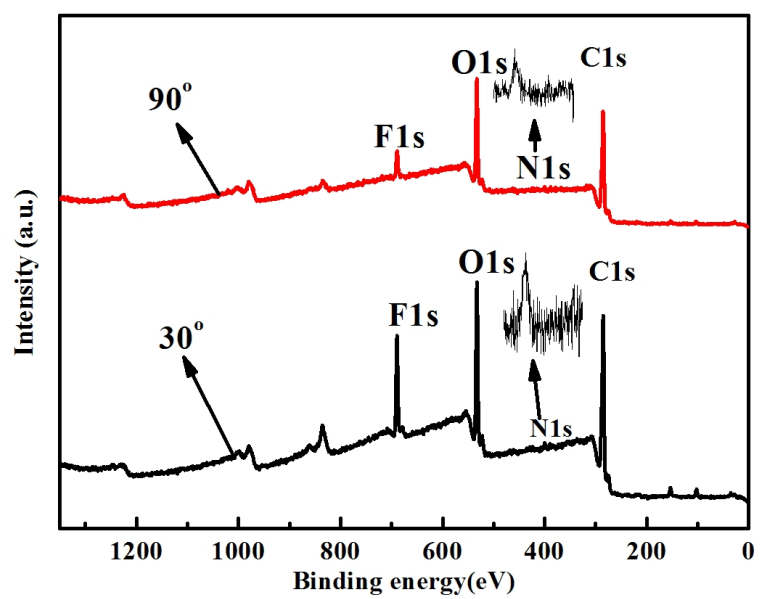

Fig. 3. XPS survey spectra of FPU films obtained for sample 6 at different incident angles.

Table 2 lists the atomic concentration percentages which were calculated from the curves in Fig. 3. The Table shows that the fluorine concentration is 13.2 at.\% at the incident angle of $30^{\circ}$, which is higher than that the content of 5.9 at.\% at the incident angle of $90^{\circ}$ and average bulk content of 10.0 at.\%. It can be concluded that the fluorine atoms are preferentially located and enriched at the surface of the film, which results in decreasing of surface free energy. Moreover, the fluorine atoms could be self-organized in the process of film forming due to the tendency of fluorinecontaining groups to migrate onto the film-air interface, so the content of the fluorine displays a gradient distribution from the film-air interface to the film-glass interface [21].

Fig. 4 presents the corresponding high resolution XPS spectra of FPU films obtained for sample 6.

Obviously, the signal intensity of fluorine at $30^{\circ}$ is higher than that at $90^{\circ}$; however, there is no obvious change for other elements at different incident angles. Single symmetrical peaks of N1s (a), O1s (b) and F1s (c) have been obtained, while the spectrum of $\mathrm{C} 1 \mathrm{~s}$ shows a complex pattern of peaks extending over a $10 \mathrm{eV}$ range due to chemically different types of carbon. In addition, four peaks of $\mathrm{C} 1 \mathrm{~s}$, have been found by curve-fitting of $\mathrm{C} 1 \mathrm{~s}$ at different incident angles which are shown in Fig. 5 after calibrating by a $\mathrm{C}-\mathrm{C}$ peak position $(285.0 \mathrm{eV})[22]$.

As shown in Fig. 5, the typical peak of $-\mathrm{CF}_{3}$ with binding energy of $293.6 \mathrm{eV}\left(\mathrm{C}_{4}\right)$ confirms the successful introduction of DFMA. Furthermore, the peaks with the binding energy of $285.0 \mathrm{eV}\left(\mathrm{C}_{1}\right), 286.9 \mathrm{eV}\left(\mathrm{C}_{2}\right)$ and $288.9 \mathrm{eV}$ $\left(\mathrm{C}_{3}\right)$ can be attributed to $\mathrm{C}-\mathrm{C}, \mathrm{COO}$ [24] and $\operatorname{NCOO}(\mathrm{C}-\mathrm{F})[25,26]$, respectively. The percentages of functional groups are listed in Table 3. It is obvious that the concentration of $-\mathrm{CF}_{3}$ at the filmair interface is higher than that at the film-glass interface, which decreases the surface free energy.

\subsection{Measurements of hydrophobic prop- erties of FPU films}

Fig. 6 shows the water CA values for FPU films with different fluorocrylate monomer concentrations obtained by measuring water drop deposited on the film surface for the first time. 
Table 2. Elemental contents of FPU films prepared from sample 6.

\begin{tabular}{ccccc}
\hline Incident angle $\left({ }^{\circ}\right)$ & $\mathrm{C}($ at.\%) & $\mathrm{N}($ at.\%) & $\mathrm{O}($ at.\%) & $\mathrm{F}($ at.\%) \\
\hline \hline 30 & 59.8 & 1.0 & 26.0 & 13.2 \\
90 & 65.0 & 1.1 & 28.0 & 5.9 \\
\hline
\end{tabular}
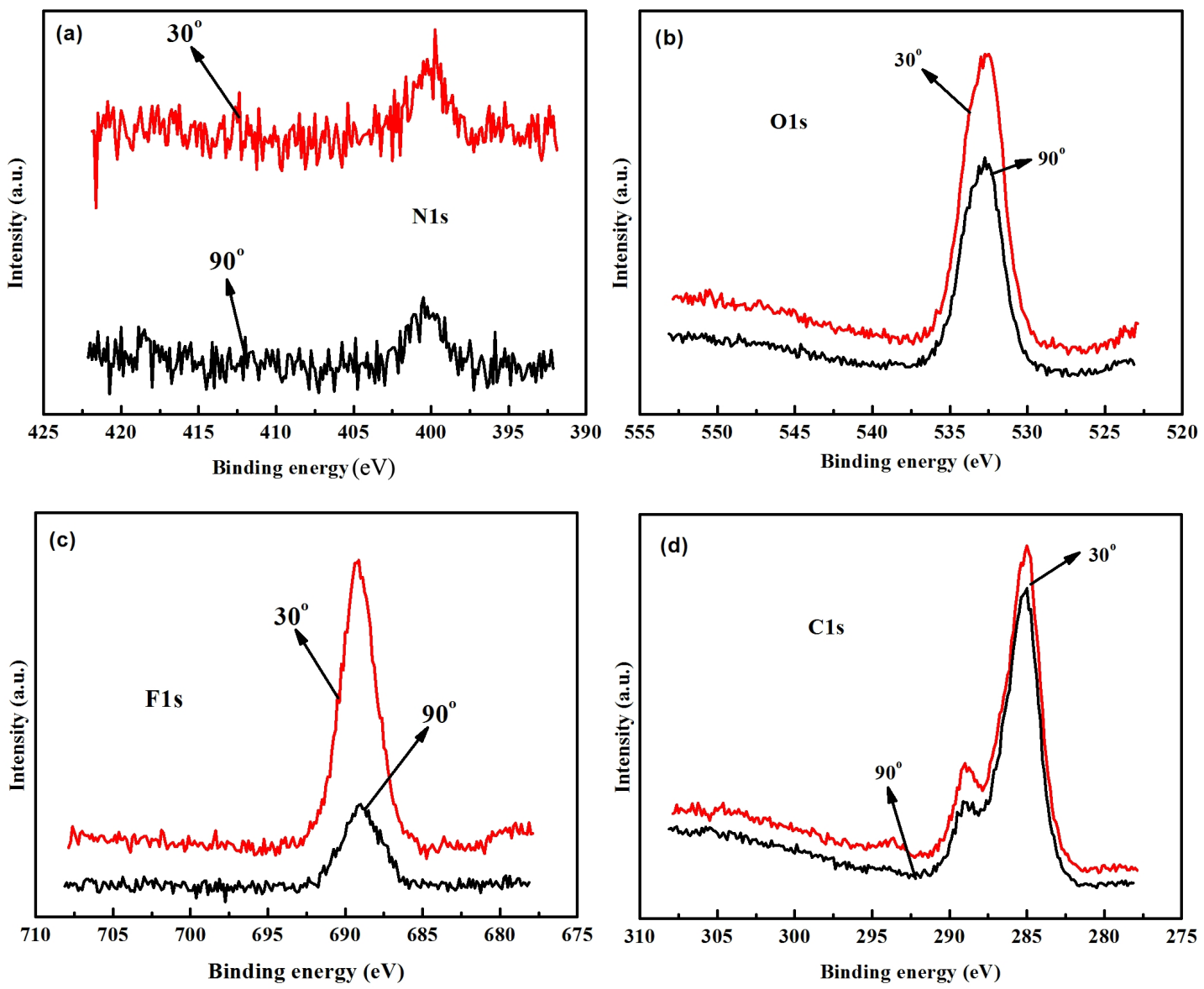

Fig. 4. High resolution XPS spectra of FPU films obtained for sample $6\left(\mathrm{~N}_{1 \mathrm{~s}}(\mathrm{a}), \mathrm{O}_{1 \mathrm{~s}}(\mathrm{~b}), \mathrm{F}_{1 \mathrm{~s}}\right.$ (c) and $\left.\mathrm{C}_{1 \mathrm{~s}}(\mathrm{~d})\right)$.

Obviously, the hydrophobicity of the FPU films depends on the fluoroacrylate monomer concentration. The CA increases sharply by increasing the concentration of DFMA from 0 to $16 \mathrm{wt} . \%$. The maximum CA value of $99^{\circ}$ (with the standard deviation of $5.6 \%$ ) has been obtained for the DFMA concentration of $22 \mathrm{wt} . \%$, which is in accordance with the theoretical surface energy of DFMA. However, the CA value stops increasing and shows a plateau value when the concentration of DFMA is above $22 \mathrm{wt} \%$, which is due to the reduction of conversion and saturation of fluorinate monomer at the film surface by continually increasing fluoroacrylate monomer concentration. The water resistance of FPU films was assessed by measuring CA value at different contact time as shown in Fig. 7.

From Fig. 7, we can see that the CA value of FPU film decreases with the increasing of contact time because of the existence of hydrophilic groups, such as $-\mathrm{COOH}$ and $-\mathrm{OH}$, in the hydroxyl-containing perfluoroacrylate copolymers. However, the film with the fluoroacrylate monomer 
Table 3. Surface chemical functionalities and contents of FPU film for sample 6.

\begin{tabular}{ccccc}
\hline Incident angle $\left({ }^{\circ}\right)$ & $\mathrm{C}-\mathrm{C}($ at. \%) & $-\mathrm{COO}($ at.\%) & $\mathrm{NCOO}(\mathrm{C}-\mathrm{F})($ at.\%) & $-\mathrm{CF}_{3}$ (at.\%) \\
\hline \hline 30 & 58.5 & 27.7 & 11.6 & 2.2 \\
90 & 62.0 & 23.3 & 13.4 & 1.3 \\
\hline
\end{tabular}
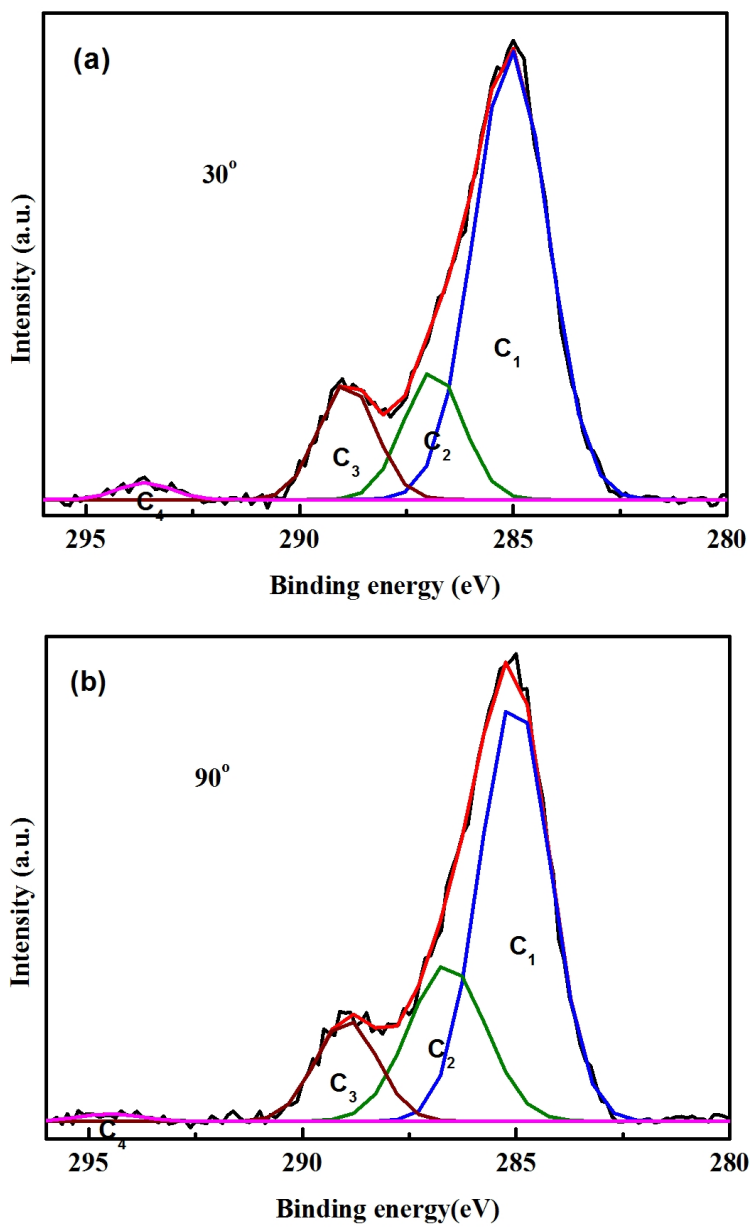

Fig. 5. Curve-fitting C1s of FPU film obtained for sample 6 at incident angles of $30^{\circ}$ (a) and $90^{\circ}$ (b).

concentration of 22 wt.\% shows the similar water resistance as the films with the fluoroacrylate monomer concentrations of 16 and $32 \mathrm{wt} . \%$. The introduction of massive $-\mathrm{CF}_{3}$ could decrease the surface free energy of FPU film. However, the degree of cross linking of FPU film would decrease because of the steric hindrance of fluoroacrylate monomer, which results in the weak water resistance.

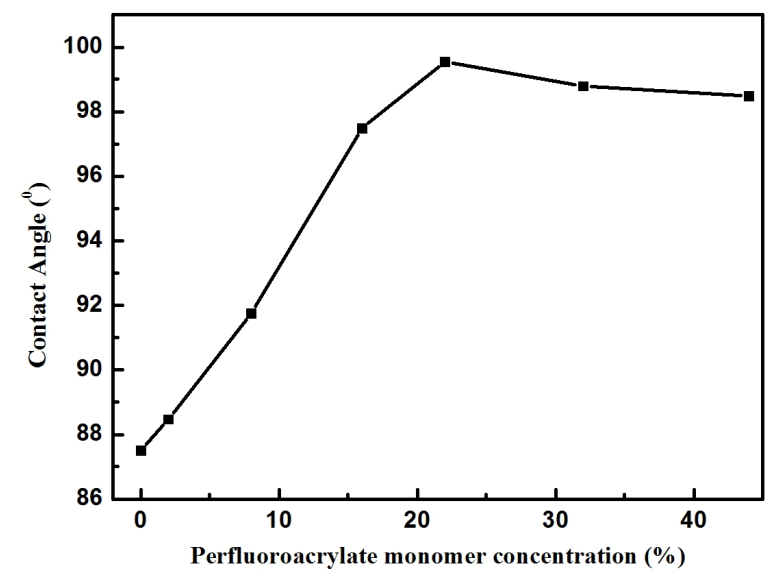

Fig. 6. CA values of FPU films with different fluoroacrylate monomer concentrations.

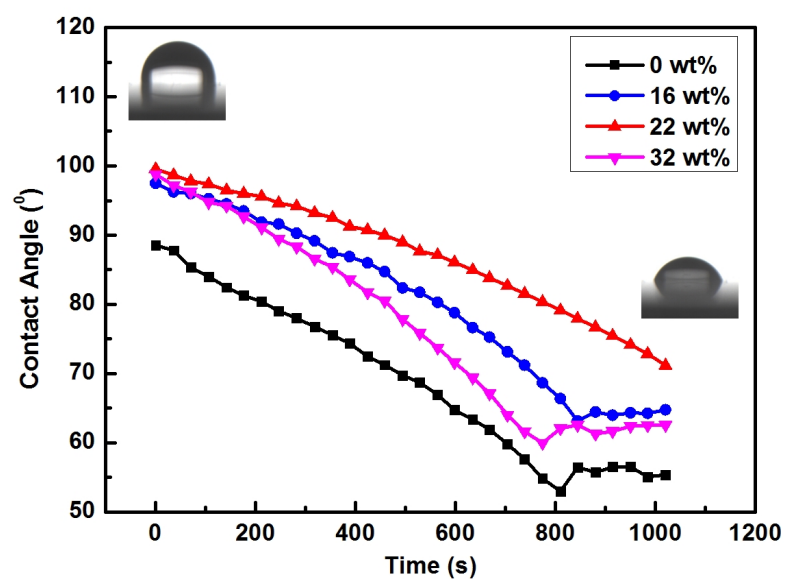

Fig. 7. Time dependence of CA values of FPU films with different fluoroacrylate monomer concentrations.

\subsection{Surface topography of FPU films}

SEM and AFM images are presented for the comparison of the surface topographies of FPU films prepared with different fluoroacrylate monomer contents ( $0 \mathrm{wt} . \%$ and $22 \mathrm{wt} . \%)$, as shown in Fig. 8. 

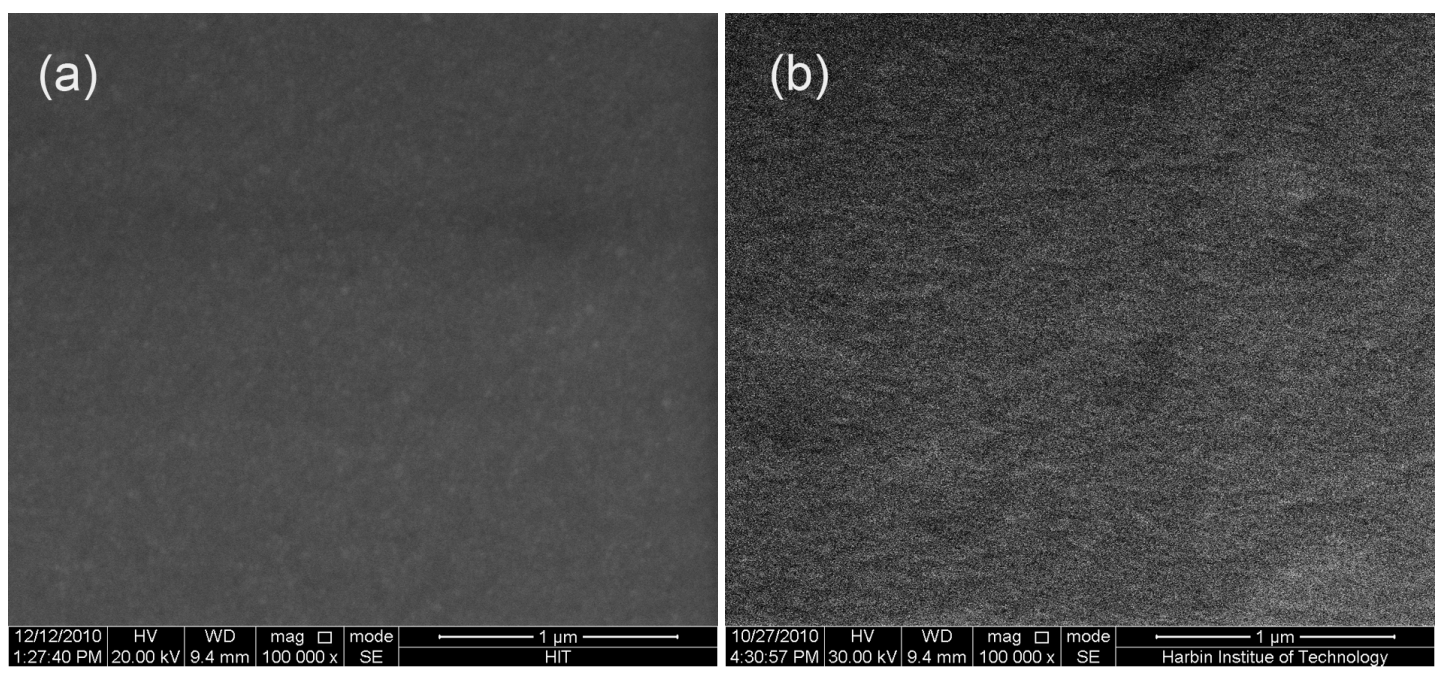

(c)

(d)
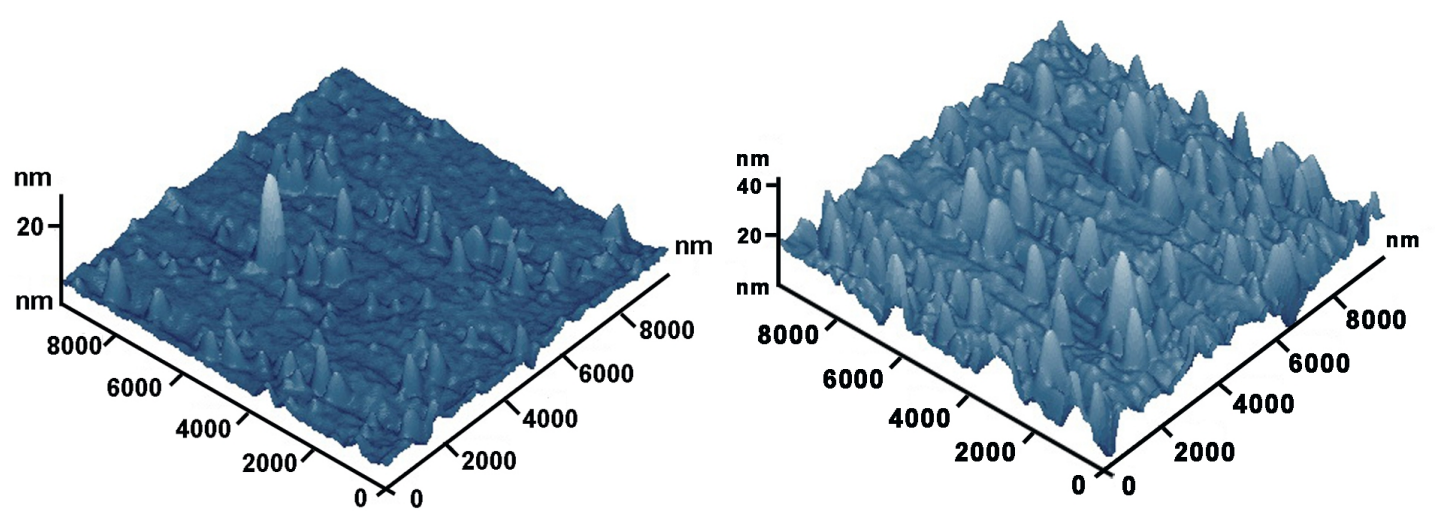

Fig. 8. SEM (a, b) and AFM (c, d) images of FPU films with different fluoroacrylate monomer concentrations (0 wt.\% (a, c) and 22 wt.\% (b, d)).

\subsection{Thermal stability of FPU films}

The thermal stability of FPU films with different fluoroacrylate monomer concentrations were evaluated from TGA and DTG data and the corresponding curves are shown in Fig. 9. The thermal degradation of PU has been studied by many researchers, and the results indicate the existence of two stages: the first one is caused by the degradation of hard segments, whereas the degradation of soft segments is responsible for another stage [27]. From Fig. 8, it can be clearly seen that there are two different degradation steps involved. At the first degradation step, the degradation temperature decreases with the increasing of fluoroacrylate monomer concentration, which can be attributed to the decreasing of cross linking degree of hard segment because of the introduction of fluoroacrylate monomer. However, the degradation temperature of FPU film with high fluorine concentration is a little higher than that with low fluorine concentration at the second stage, which can be explained as the existence of more $\mathrm{C}-\mathrm{F}$ in the soft segment with increasing of fluoroacrylate monomer concentration.

\subsection{Transparency of FPU films}

Fig. 10 shows the optical photographs of FPU films with different fluoroacrylate monomer concentrations. 


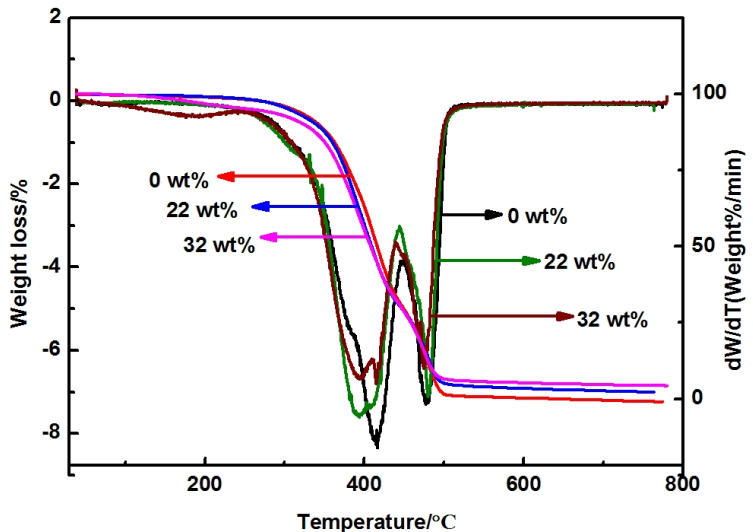

Fig. 9. TG and DTG thermograms of the FPU films with different fluoroacrylate monomer concentrations.

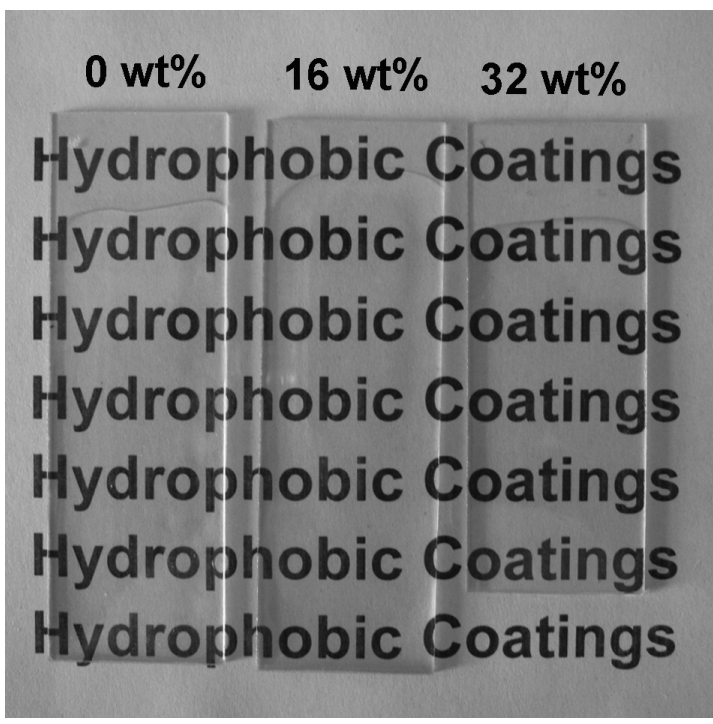

Fig. 10. Optical photographs of FPU films with different fluoroacrylate monomer concentrations.

As we can see in Fig. 10, the FPU films show unobvious differences in transparency. In order to distinguish the difference in transparency, the UV-Vis spectra of FPU films were recorded and presented in Fig. 11.

As shown in Fig. 11, the transmittance of the FPU films is different. The fluorine-free film shows a good transmittance in the visible wavelength range ( 380 to $760 \mathrm{~nm}$ ) with a value of above $95 \%$. The transmittance decreases with increasing of fluoroacrylate monomer content in the copolymer.

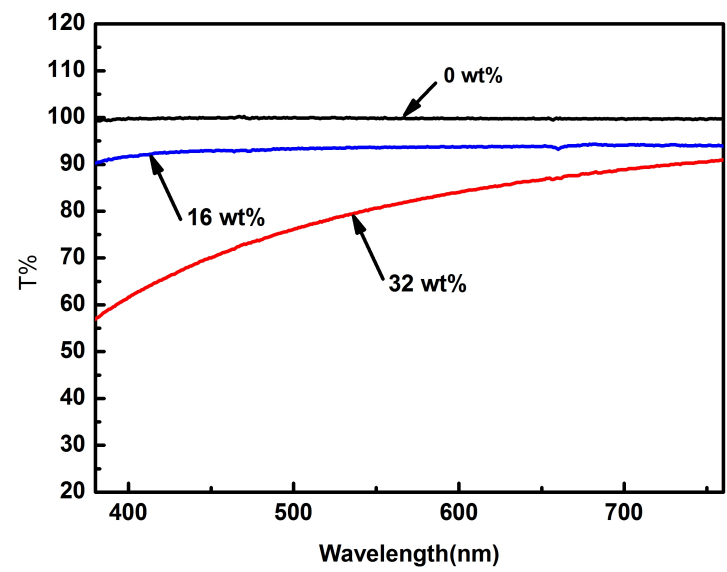

Fig. 11. UV-Vis spectra of FPU films with different fluoroacrylate monomer concentrations.

Nevertheless, the FPU film with the fluoroacrylate monomer content of $16 \mathrm{wt} \%$ shows a high transmittance of more than $90 \%$ in the whole visible wavelength range. The transmittance of the FPU film with the fluorinated monomer of $32 \mathrm{wt} \%$ is only about $55 \%$ at $380 \mathrm{~nm}$, and increases to $85 \%$ approximately at $760 \mathrm{~nm}$. In conclusion, the transmittance of FPU film decreases with the increasing of fluoroacrylate monomers concentration. The micro-phase separation degree of FPU film increases with the increasing of fluoroacrylate monomer concentration, which would result in much higher light scattering and low transmittance of FPU film.

\section{Conclusions}

Transparent FPU films with hydrophobic properties were obtained by crosslinking of HDI trimer with hydroxyl-containing fluoroacrylate copolymers synthesized by free-radical solution polymerization. The $-\mathrm{CF}_{3}$ and $-\mathrm{OH}$ functional groups were both successfully introduced in the copolymers, and the copolymer reacted with the HDI trimer completely. XPS analyses at different incident angles indicated that fluorine element was enriched on the surface of the sample. The hydrophobicity of the film increased with increasing the concentration of fluoroacrylated monomer of DFMA, and there was a critical concentration value of 22 wt.\% with the maximum CA value of about 
$99^{\circ}$. In the view of transparency and hydrophobicity, the addition of fluoroacrylate monomer should not exceed $22 \mathrm{wt} . \%$. The decomposition temperature of hard segment decreased and that of soft segment increased with the increasing of fluoroacrylate monomer concentration.

\section{Acknowledgements}

The authors gratefully acknowledge the National Natural Science Foundation of China (51402073), the Fundamental Research Funds for the Central Universities and the Program for Innovation Research of Science in Harbin Institute of Technology, China (T201410), and the Excellent Academic Leaders Foundation of Harbin, China (2014RFXXJ017), for financial support.

\section{References}

[1] Sawada H., Suzuki M., Mugisawa M., Polym. Advan. Technol., 17 (2006), 66.

[2] Cui X. J., Zhong S.L., GaO Y., Wang H. Y., Colloid Surface A, 324 (2008), 14.

[3] Dai J. B., Zhang X. Y., Chao J., Bai C. Y., J. Coat. Technol. Res., 4 (2007), 283.

[4] Ameduri B., Bongiovanni R., Malucelli G., Pollicino A., Priola A., J. Polym. Sci. Pol. Chem., 37 (1999), 77.

[5] Gupta M., Gleason K. K., Langmuir, 22 (2006), 10047.

[6] Lazzari M., Chiantore O., Castelvetro V., Polym. Int., 50 (2001), 863.

[7] Ravenstein van L., Ming W., Grampel Van DE R.D., LINDE VAN DER R., WITH DE G., LOONTJENS T., Thüne P.C., Niemantsverdriet J.W., Macromolecules, 37 (2004), 408.

[8] Toniolo L., Poli T., Castelvetro V., Manariti A., Chiantore O., Lazzari M., J. Cult. Herit., 3 (2002), 309.

[9] Dreher W.R., Jarrett W.L., Urban M.W., Macromolecules, 38 (2005), 2205.
[10] Malshe V.C., Sangai N.S., Prog. Org. Coat., 53 (2005), 207.

[11] Gui T.J., Wei H., Zhao Y., Wang X.L., WAnG D.J., Xu D.F., Chinese J. Polym. Sci., 24 (2006), 575.

[12] Saidi S., Guittard F., Geribaldi S., Polym. Int., 51 (2002), 1058.

[13] Lazzari M., Chiantore O., Castelvestro V., Polym. Degrad. Stabil., 79 (2003), 345.

[14] Chiantore O., Lazzari M., Aglietto M., Castelveto V., Ciiardelli F., Polym. Degrad. Stabil., 67 (2000), 461.

[15] Nakajima A., J. Ceram. Soc. Jpn., 112 (2004), 533.

[16] Nostro P. L., Adv. Colloid Interfac., 56 (1995), 245.

[17] Zisman W. A., Ind. Eng. Chem. Res., 55 (1963), 19.

[18] Gnanappa A.K., O’Murchu, Slattery O., Peters F., Aszalós-Kiss B., Tofall S.A.M., Polym. Degrad. Stabil., 93 (2008), 2119.

[19] Feng J.C., Huang W., Eur. Polym. J., 43 (2007), 3773.

[20] Amigoni S., De Givenchy E.T., Dufay M., GuitTARD F., Langmuir, 25 (2009), 11073.

[21] Chen Y.J., Cheng S.Y., Wang Y.F., Zhang C.C., J. Appl. Polym. Sci., 99 (2006), 107.

[22] Deshmukh R.R., Shetty A.R., J. Appl. Polym. Sci., 104 (2007), 449.

[23] Kassis C.M., Steehler J.K., Betts D.E., Guan Z.B., Romack T.J., Simone DE J.M., Linton R.W., Macromolecules, 29 (1996), 3247.

[24] Inagaki N., Tasaka S., Hiramatsu H., J. Appl. Polym. Sci., 71 (1999), 2091.

[25] Girardeaux C., Druet E., Demoncy P., DelaMAR M., J. Electron. Spectrosc., 74 (1995), 57.

[26] Crassous I., Groult H., Lantelme F., Devilliers D., Tressaud A., Labrugere C., Dubois M., Belhomme C., Colisson A., Morel B., J. Fluorine Chem., 130 (2009), 1080.

[27] Lu M.G., LeE J.Y., Shim M.J., KIM S.W., J. Appl. Polym. Sci., 85 (2002), 2552.

Received 2012-04-26

Accepted 2015-05-01 